\title{
Multi-Sectoral Participatory Design of a BabyWASH Playspace for Rural Ethiopian Households
}

\author{
Sophie Budge, ${ }^{1}$ Alison Parker, ${ }^{1 \star}$ Paul Hutchings, ${ }^{2}$ Camila Garbutt, ${ }^{3}$ Julia Rosenbaum, ${ }^{4}$ Tizita Tulu, ${ }^{5}$ Fitsume Woldemedhin, ${ }^{6}$ \\ Mohammedyasin Jemal, ${ }^{6}$ Bhavin Engineer, ${ }^{7}$ and Leon Williams ${ }^{8}$ \\ ${ }^{1}$ Cranfield Water Science Institute, Cranfield University, Cranfield, United Kingdom; ${ }^{2}$ Faculty of Engineering and Physical Sciences, University of \\ Leeds, Leeds, United Kingdom; ${ }^{3}$ People in Need UK, London, United Kingdom; ${ }^{4}$ FHI360/United States Agency for International Development \\ WASHPaLS Project, Washington, District of Columbia; ${ }^{5}$ Concern Worldwide, Addis Ababa, Ethiopia; ${ }^{6}$ People in Need, Hawassa, Ethiopia; ${ }^{7}$ B.E. \\ Design, Cambridge, United Kingdom; ${ }^{8}$ Centre for Competitive Creative Design, Cranfield University, Cranfield, United Kingdom
}

\begin{abstract}
Growing evidence suggests current water, sanitation, and hygiene interventions do not improve domestic hygiene sufficiently to improve infant health, nor consider the age-specific behaviors which increase infection risk. A household playspace (HPS) is described as one critical intervention to reduce direct fecal-oral transmission within formative growth periods. This article details both the design and development (materials and methods), and testing (results) of a HPS for rural Ethiopian households. Design and testing followed a multi-sectoral, multistep participatory process. This included a focus group discussion (FGD), two user-centered and participatory design workshops in the United Kingdom and Ethiopia, discussions with local manufacturers, and a Trials by Improved Practices (TIPs) leading to a final prototype design. Testing included the FGD and TIPs study and a subsequent randomized controlled feasibility trial in Ethiopian households. This multi-sectoral, multistage development process demonstrated a HPS is an acceptable and feasible intervention in these low-income, rural subsistence Ethiopian households. A HPS may help reduce fecal-oral transmission and infection-particularly in settings where free-range domestic livestock present an increased risk. With the need to better tailor interventions to improve infant health, this article also provides a framework for future groups developing similar material inputs and highlights the value of participatory design in this field.
\end{abstract}

\section{INTRODUCTION}

In certain lower-middle-income countries, poor infant (age less than 2 years) health outcomes remain a key public health issue. Poor nutrition can leave infant and young children underweight, weak, and thus vulnerable to infections ${ }^{1}$ - primarily from a weakened immune system. Where growth is interrupted, the cycle continues. ${ }^{2}$ Diarrheal disease remains highly prevalent, ${ }^{3}$ despite recent reductions in mortality, ${ }^{4}$ and infants may experience up to eight diarrheal episodes a year before the age of 2 years, ${ }^{3}$ suggesting very early, chronic pathogen exposure. Repeated diarrhea and infection create a vicious cycle that can negatively impact linear growth ${ }^{5}$ and both cognitive and psychosocial development. ${ }^{6}$ As such, stunting remains high in certain areas. ${ }^{7}$ Trends over time show improved water, hygiene, sanitation (WASH), and the hygiene environment contribute significantly to accelerations in average height in infants and children. ${ }^{8,9}$ With an aim to interrupt fecal-oral transmission and thus improve undernutrition (in terms of linear growth failure), UNICEF linked improved household WASH to their undernutrition framework almost three decades ago. ${ }^{10}$ Substantial evidence suggests WASH availability, quality, and consistent use contribute to good infant health. ${ }^{11,12}$ However, large, randomized controlled trials testing improved household WASH (with or without a nutrition component) have shown variable, mostly insignificant, effects. ${ }^{13-15}$ Thus, it is likely that to improve infant health outcomes, intervention design requires an overhaul to improve environmental hygiene. Although it is presently unclear what it will consist of, a call for "Transformative WASH" necessitates a delivery of each element of WASH in tandem, and at substantial scale and quality. ${ }^{16}$ This would include, but is not limited to, safe and consistent water quality and quantity and improved sanitation at the community level and handwashing facilities with soap and separation of

*Address correspondence to Alison Parker, Cranfield Water Science Institute, Cranfield University, College Road, Cranfield MK43 OAL, United Kingdom. E-mail: a.parker@cranfield.ac.uk animals and their feces from living environments within the home. Such a package must be tailored to address the local exposure context and pathogen burden as well as socioeconomic conditions. Improving conditions for the most resourcepoor households will require these interventions (whether technical, structural, or behavioral) to be at once effective, feasible, and affordable. This may achieve the conditions necessary to improve infant health. ${ }^{17}$

If WASH interventions aim to improve infant health, they must also be more effectively tailored toward this age-group. The concept of "BabyWASH" was recently established to promote intervention components which address the age- and behaviorrelated pathways of infant fecal-oral transmission. ${ }^{18}$ Mouthing of contaminated objects is a particular risk pathway linked to unrestricted play and exploration, particularly in areas where domestic animals share living spaces. ${ }^{19-22}$ Research describes how animal pathogen reservoirs contribute to the contamination of multiple fecal-oral pathways ${ }^{22-24}$ and transmission between animals and infants. ${ }^{25,26}$ Furthermore, associations exist among animal proximity and infection, malnutrition, and environmental enteric dysfunction (EED) - a subclinical condition affecting the gut, which limits nutrient absorption and thus growth. ${ }^{27,28} \mathrm{~A}$ household playspace (HPS), that is, a protective, walled enclosure, is one intervention component which may help prevent direct ingestion of soil and feces ${ }^{19,29}$ and provide protection from contaminated surfaces. ${ }^{30,31}$ The WHO has deemed a HPS a "critical intervention" component of WASH ${ }^{32}$ that may help prevent infection and improve infant health. ${ }^{33,34}$ However, there is a lack of data around the potential of a HPS to reduce pathogen exposure and no reported development process which might serve as a template. This remains a barrier to both the donor community and for research groups developing and testing intervention components which address infant needs and behaviors.

Article aim and structure. This article aims to detail the design and testing of a HPS for a low-income context. The design and testing processes follow formative research between Cranfield University, the nongovernmental organization 
for People In Need (PIN), and Hawassa University, Ethiopia, demonstrating the importance of direct fecal-oral transmission to infant infection. ${ }^{22,35,36}$ The final HPS prototype resulting from this design process was tested in a randomized, controlled feasibility trial, the Campylobacter-Associated Malnutrition Playspace Intervention (CAMPI) trial, which assessed the feasibility of a HPS in rural Ethiopian households. ${ }^{37}$ Certain outcomes from the feasibility trial are presented here in this article to demonstrate feasibility of the HPS as an intervention modality. Full findings from the trial are reported separately. ${ }^{37}$

It was speculated that the development of best practice guidelines on developing material interventions within WASH scope would facilitate knowledge sharing across research groups. By detailing these processes, the team aims to provide a framework for future interventions developing similar BabyWASH material inputs. Therefore, this article is divided into three sections. First, the article reviews current evidence and ongoing research as part of a WASH intervention. Second, the Materials and Methods section describes the development of a HPS through a needs- and evidence-based multi-sectoral, multi-step participatory process. Third, the team recognized the need for further data on feasibility outcomes which would help to assess the potential for a HPS to reduce fecal-oral transmission. Thus, the Feasibility and Testing section describes outcomes from formative testing which piloted prototypes and the final design to demonstrate acceptance and adherence. Figure 1 illustrates the components of the design and testing processes as they pertain to the layout of this article.

\section{SECTION 1: CURRENT EVIDENCE ON PLAYSPACES OR PLAYMATS}

The potential for a HPS to improve infant health outcomes has been, or is currently being, studied by research teams and nongovernmental organizations across different contexts. However, as a new intervention modality, many of the results are pending. Details on the design, fidelity measures such as uptake, maintenance, time use, microbiological data, or infant-related outcomes such as reduction in fecal-oral contact or diarrhea are limited. Some implementers have incorporated playmats without a supporting evidence base, but through evaluation are contributing. Through a brief review of current studies, this initial section highlights the need for more comprehensive and standardized design and testing research. Thus, this section first looks at efforts that include a playmat: that is, a flat fabric and/or plastic sheet with no barrier/sides. It then reviews current HPS research.

A randomized controlled trial of BabyWASH interventions in South Kivu in the Democratic Republic of Congo is investigating the effect of either a household playmat, playspace, or BabyWASH package to determine which format is the most effective strategy in preventing geophagy and decreasing EED. ${ }^{38}$ Results are awaited. In Ghana, a playmat was a key enabling WASH technology in the SPRING "WASH 1,000 Program" to provide a hygienic space for infants and prevent fecal-oral transmission. ${ }^{39}$ However, data on design, acceptability, uptake, and use were not collected, nor data on bacterial/fecal contamination or infant health outcomes. As part of the U.S. Agency for International Development (USAID) ENGINE Project, a small study investigated the market potential of subsidizing polyvinyl chloride playmats, marketed through micro-enterprises and local women's saving groups. ${ }^{40}$ Almost 4,000 mats were sold, and most households $(77 \%)$ reported always using the mat for the intended purpose.

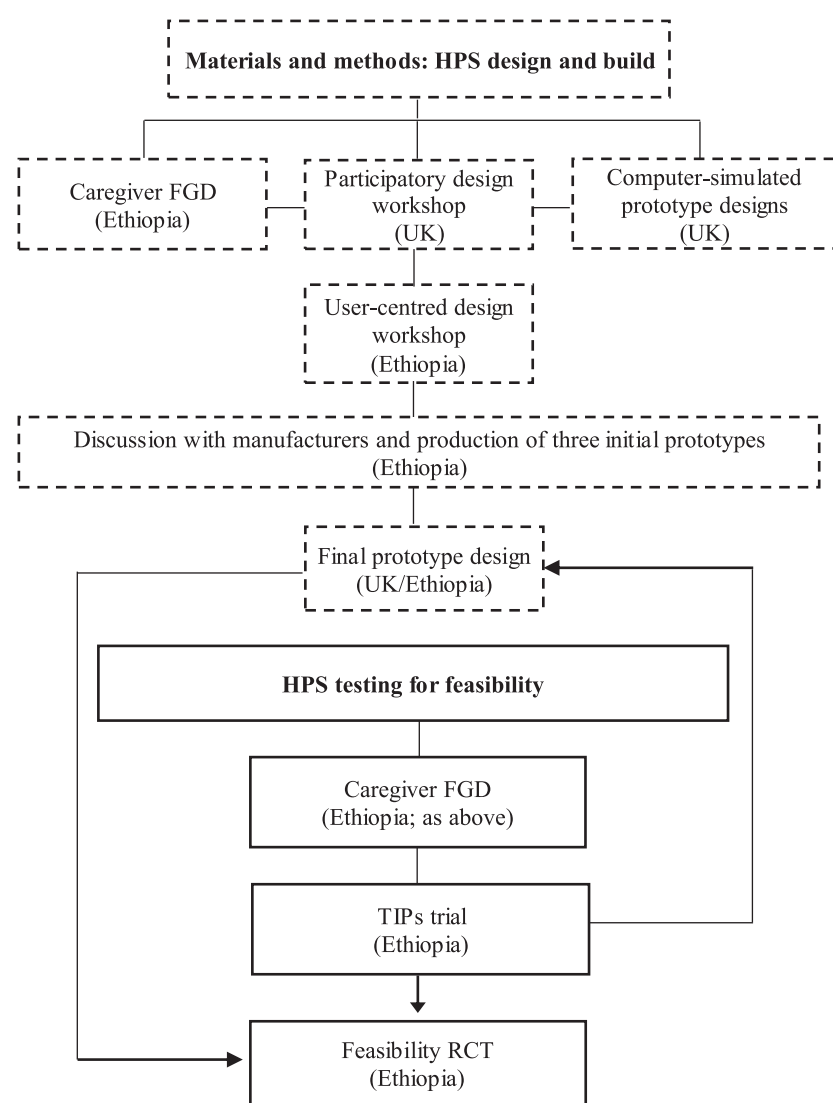

FIGURE 1. Components of the design and development and feasibility processes and the layout of this article.

However, informal follow-up indicated many mats had tears after a short time, and when infants became slightly mobile, they were ineffective (Save the Children, personal communication).

Thus, most studies to date examining the efficacy of a hygienic space have used flat mats with no walls. Although a playmat may be beneficial during travel and may help prevent some fecal-oral transmission, it may not fully prevent fecal ingestion from dirty floors, nor restrict animal or infant movement onto and off of the mat, nor are they often durable. Instead, of a playmat, few studies have tested a walled playspace. This design would better this prevent free movement and generally better demarcate a space that can provide better caregiver control. The two options of an imported plastic HPS and a locally sourced plastic playmat were part of the sanitation hygiene infant nutrition efficacy trial in Zimbabwe. Extensive formative research informed the rationale and assessed demand ${ }^{29,34}$ and delivery of the intervention was high ${ }^{15}$; however, results suggested neither option reduced infection. ${ }^{41}$ On spot check, HPS across intervention arms was 92-93\% clean, but further data are pending on use behaviors and duration of use, and whether and by what magnitude either option reduced fecal-oral transmission. A team recently described a thorough, evidencebased design process to create an acceptable and communitybuilt BabyWASH HPS in Zambia. ${ }^{33}$ Although locally designed by the community and a solid, durable structure, the HPS was a fixed space situated outdoors. The study aimed to reduce fecal-oral transmission within the household, so an outdoor space may not have interrupted main domestic transmission pathways. It may also have encouraged other infants or children to enter, perhaps introducing other sources of contamination. It may also be more 
difficult for mothers to consistently watch their infants and lead to insufficient supervision when occupied; it was noted that the HPS introduced additional work that meant the mother spent less time working in the fields. ${ }^{33}$ The HPS was tested alongside an imported, commercial plastic model. Reported use was similar between the two types, but caregivers expressed concerns over perceived durability and the potential for infants to climb out of the plastic model. This model was lightweight, collapsible, and visually appealing, but the cost was prohibitive to these subsistence livelihood households. In Ethiopia, the USAID Water, Sanitation, and Hygiene Partnerships and Learning for Sustainability (WASHPaLS) project engaged rural parents, nongovernmental organizations health extension workers (HEWs), and design specialists to design infant HPS from locally sourced materials. These were tested alongside one low-end commercial HPS for feasibility of use and cleaning, appeal, perceived value and Escherichia coli contamination. ${ }^{42}$ The designed HPS were immensely appealing to caregivers, who reported a number of hygiene, caregiving, and developmental benefits, however, reported and observed use cast doubts on their effectiveness at substantially reducing pathogen exposure.

Therefore, a lack of evidence around the effectiveness of a walled HPS in reducing pathogen exposure remains a barrier to the donor community to invest as part of a more comprehensive WASH package. Another issue is affordability: currently, there is no HPS product which is within financial reach of the rural poor. Without a low-cost, bulk-produced option, implementation of a HPS intervention would require intensive donor support which is not scalable. Attention is thus shifting to explore options for a locally sourced and produced HPS which, if found effective and feasible, might offer a scalable program option. This assumes that a locally sourced and produced HPS would be both financially accessible and would reflect local needs and preferences-also increasing uptake and continued use. Best practice suggests that involving end-users in a multi-sectoral, iterative design process is essential for designing and launching consumer products: especially so with vulnerable groups within developing countries. ${ }^{43}$ With this process, design and development takes into account local contextual needs which are critical to intervention success for both users and stakeholders.

\section{SECTION 2: MATERIALS AND METHODS}

This second section details the design and development of the BabyWASH HPS. This process was a collaboration between Cranfield Water Science Institute, the Centre for Competitive Creative Design (C4D) at Cranfield University, and PIN in the Southern Nations, Nationalities, and Peoples' Region (SNNPR), Ethiopia, and enhanced by a supporting USAID-sponsored design workshop in Ethiopia. The full process spanned 18 months and encompassed several iterative steps within the United Kingdom and Ethiopia (see Figures 1 and 2) to produce the final prototype (see Figure 3). These are as follows:

1. Focus group discussion (FGD), Ethiopia

2. Participatory design workshop and initial computersimulated designs, United Kingdom

3. User-centered design workshop, Ethiopia

4. Incorporating lessons from workshops and interactions with Ethiopian manufacturers

5. Trials by Improved Practices (TIPS)

6. Final prototype design
The methodologies of these stages are detailed in the following text. Further information is included in Supplemental Information.

Ethics. The research followed standard ethical procedures, and study aspects involving participants were approved by the Cranfield University Research Ethics Committee (CURES 4955/2018). Consent forms were translated into both Amharic and Sidamo and all participants provided written informed consent.

Focus group discussion, Ethiopia. Focus group discussion was held by PIN and Cranfield University in Sidama zone, SNNPR, in June 2018. The FGD primarily aimed to understand the need and demand for a hygienic playspace among mothers in this rural, subsistence agriculture setting. Second, the FGD aimed to gain primary insights into design requirements which were appropriate for the context. So mothers could conceptualize and discuss a hygienic playspace for infants, 7 days prior team members distributed a canvas mat $\left(1.5 \mathrm{~m}^{2}\right)$ to households. Mothers were asked to use it as an infant play area for a week. Directions were given on keeping the mat clean (wash when visibly dirty and after the infant or an animal defecated or urinated, with water and soap). Mothers were also asked to consider how they would improve the design to better meet their infant's needs and improve their health. Further methodological details are in Supplemental Material S1.

The FGD highlighted that mothers were concerned about feces from animal (particularly cattle and poultry) and human sources within the home as a risk factor for infant illness. Mothers recognized that during crawling and play, infants were likely to mouth dirty objects and feces, which contributed to illness:

Yes we are worried because if they took this to their mouth they will get disease as it contains bacteria.

Although other research has suggested infant feces may be perceived as benign, ${ }^{34}$ mothers perceived the same severity of risk:

Both adult faeces and child faeces are the same, they cause disease. So to prevent all of these things we clean the compound before we leave the children to play.

Having had the canvas mat for a week, mothers were positive about the benefits of a hygienic space for their infant. Mothers could continue their work and watch the infant while providing a more hygienic surrounding:

If our child plays on the mat he doesn't get the dirty material in his mouth, it's a way to keep him clean.

I can continue with my activities if the baby is on a mat.

It has additional value for us to protect from dirty things but still we are with him.

Mothers reported cleaning the mat was easy and they were willing to keep it clean:

Even if they urinate on the mat or defecate on the mat, we can clean it easily. We wash it and put it in the sun and then bring it back into the house. 


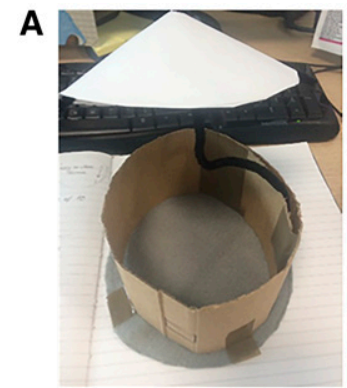

B

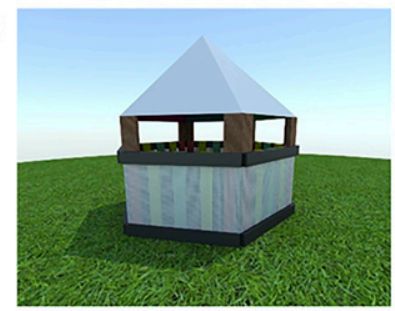

C

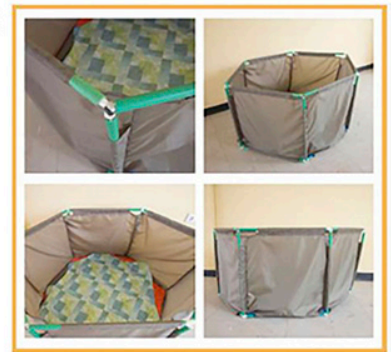

D

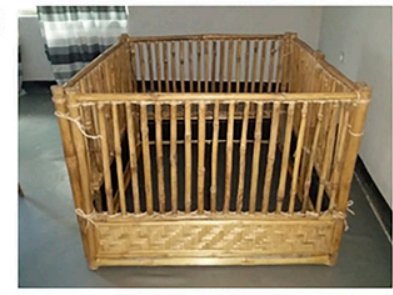

E

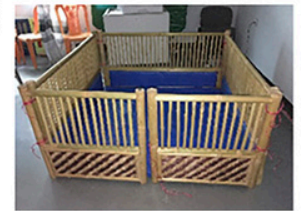

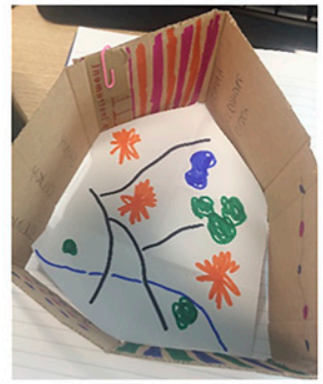
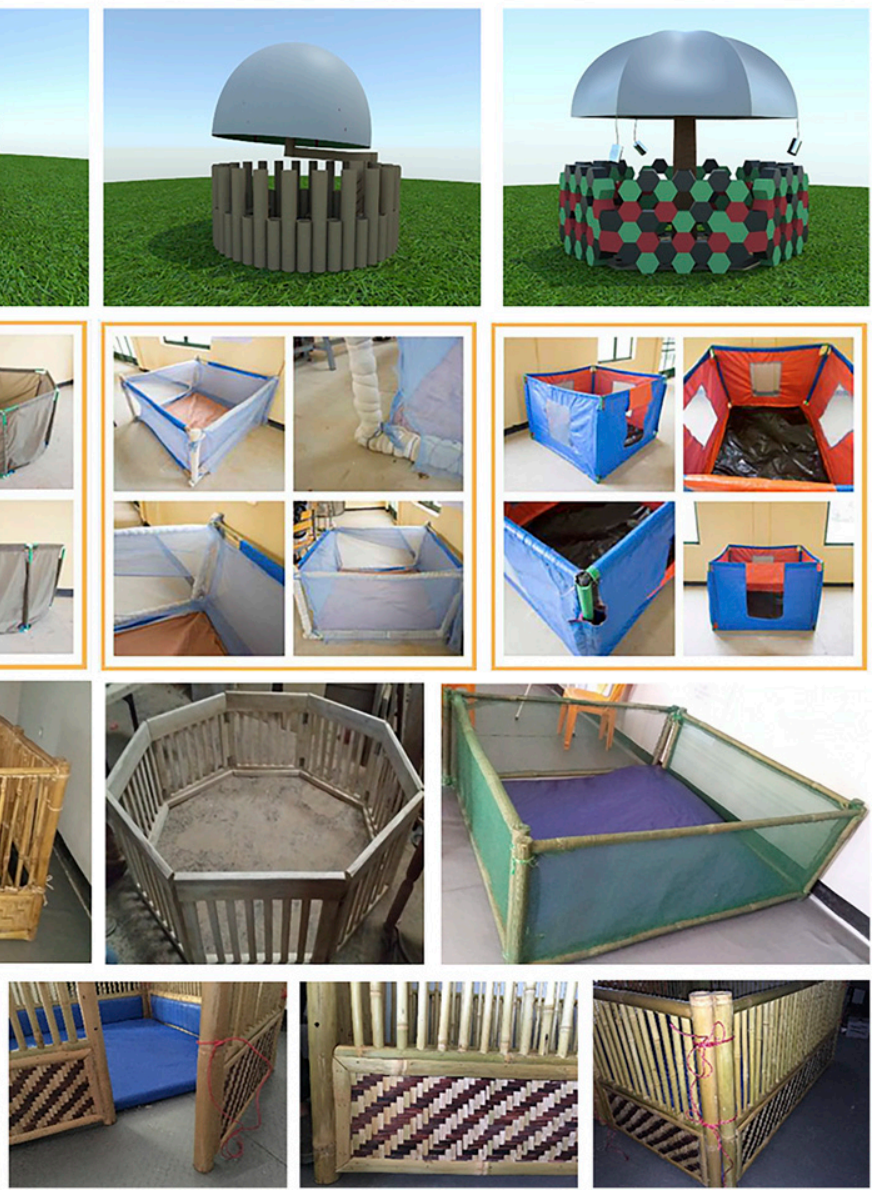

Figure 2. Design evolution of the playspace to the final prototype design. This figure appears in color at www.ajtmh.org.

Commenting on the design, mothers all agreed the mat had benefits but would not prevent animals from contaminating it nor remove the risk of feces:

If the mat has its own protection this would protect them [infants] from going outside of the mat and stop animals from going in.

It must have sides. The animals can easily access the mat if we leave the baby at the moment.

Findings from the FGD provided valuable feedback on perceived value, demand, and potential uptake of a HPS, as well as initial insights into user needs for the design.

Participatory design workshop and computer-aided prototype design, United Kingdom. The initial design stage for the HPS involved a 4-hour participatory design workshop held at Cranfield University. This was facilitated by researchers from the Cranfield Water Science Institute and facilitated by C4D, while including some parents. The aim of the first workshop was to generate initial prototype designs which could be computer simulated and taken to the second workshop for further development. In the workshop, the team reflected on feedback from the FGD and other developmental, emotional, and safety needs and requirements of the infant, caregivers, and stakeholders. Following a presentation of the research background and workshop aims, a facilitated group discussion helped attendees to list design requirements, the following nine of which were identified:

1. Keeps out domesticated animals

2. Cheap and possible to mass manufacture within the local context 


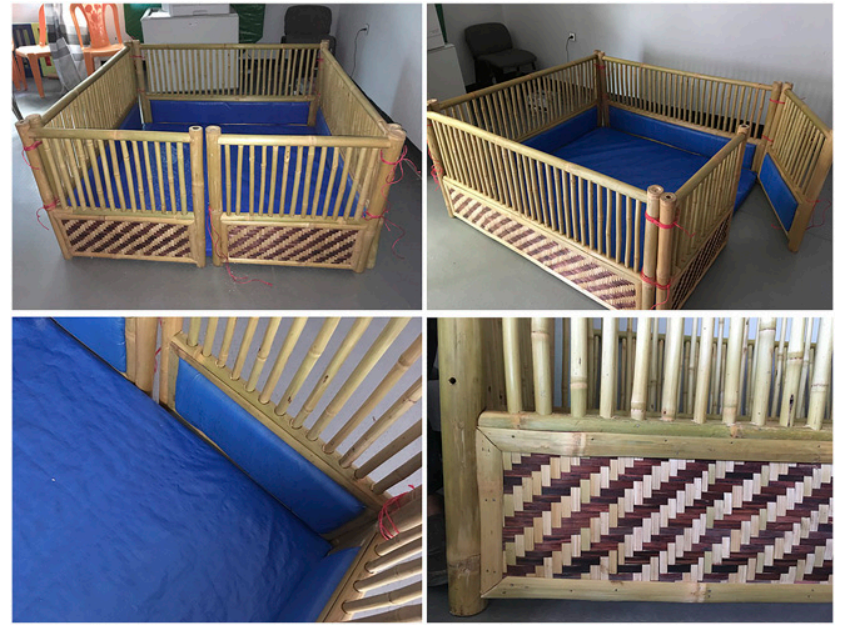

FIGURE 3. Final playspace prototype design for the Campylobacter-Associated Malnutrition Playspace Intervention trial feasibility trial. This figure appears in color at www.ajtmh.org.

3. Provides cognitive and physical stimulation to infants

4. Lightweight and easy to distribute

5. Baby is visible-parent receives reassurance

6. Requires little water to clean

7. Not made of materials that harbor bacteria

8. Can cope in local weather conditions

9. Appropriate for the cultural context of the study (e.g., livelihood patterns, maternal work burden and needs, and caregiving practices)

Considering these criteria, small groups used craft materials to develop small-scale models of a HPS (see Figure 2). These were recorded and used to develop a requirement rating scale. This was created by first assigning a value between 0 and 1.0 for each of the nine aforementioned requirements. Following, each prototype from the workshop was individually scored by assigning values $0-1.0$ to attributes listed earlier as to whether the prototype achieved that attribute. The sum was then totaled. Thus, each design had a list of scores. Ranking these scores in order gave a set of specific design features that were deemed most necessary for the final prototype designsdescribed later in the Results section. Considering this list, a design engineer at C4D created three computer-aided visualizations of different prototypes (see Figure 2). These three designs were taken by a WASH project manager at PIN to a second workshop in Ethiopia to share and further refine the designs.

User-centered design workshop, Ethiopia. A second workshop focused on user-centered design was hosted by the USAID WASHPaLS and Transform WASH Projects (implemented by Population Services International and partners). The workshop was held in Bahir Dar, Amhara, after the initial United Kingdom workshop. Bahir Dar Institute for Technical and Vocational Education and Training provided classroom and workshop spaces and staff members with various technical expertise. In conducting similar research as this team, WASHPaLS designed the workshop with aims to develop locally sourced, economical HPS models for use in their household trial. ${ }^{44}$ The iterative design process engaged 15 "users" including parents, government HEWs, local artisans, and the vocational college instructors and yielded three models that would be further refined for bulk production and household testing. The process was in three stages: gathering information, generating ideas, and prototyping/testing. People In Need's WASH project manager attended the workshop to gain insight into prototype design ideas. This second design workshop also allowed further design inputs from rural households. Users grasped the concept of a protective space, feeling it would create a "safe zone" and facilitate household chores; however, some stated this was something for "city folk" and not accessible to them. Participants particularly appreciated the visibility provided by net siding used in two of the models, allowing visibility of the infant, and so the infant did not feel isolated from the caretaker, and the removable padded mattress which facilitated cleaning. Some interviewees indicated they would be willing to pay around 250 birr (US \$8) for the product, whereas others expressed that they would rather reproduce the model at home using nails and wood rather than bamboo; this implied users themselves might produce a HPS more cheaply than a locally produced model. Thus, these participants were willing to sacrifice portability for ease of construction, and design for price. Based on feedback, one of the three prototypes was chosen to trial within homesspecifically because of the use of local materials, ease of production, portability, ventilation, and size. An additional indepth interview with a local carpenter gave insight into issues with "small-scale" production, possible modifications to economize production, demand, and willingness to pay.

Incorporating lessons from workshops and interactions with Ethiopian manufacturers. Reflecting on the findings from the United Kingdom participatory design workshop, the FGD and the user-centered design workshop with WASHPaLS, three prototypes were developed. From the computeraided designs, design complexity was scaled back, the size was reduced, and complicated roof designs were eliminated. The three prototypes varied slightly in design and incorporated key attributes deemed important, including a soft foam mat with a washable cover, a portable wooden structure, and infant visibility. People In Need WASH team members sought to identify local artisans with experience in woodwork and production. Subsequent discussions identified materials that could be easily sourced in local markets, including bamboo, foam, and cotton or canvas covers. Further discussions negotiated price and timescale. Specifications for the three prototypes, including side height and slat space, followed design and safety requirements taken from a relevant international standard (International Standards Organization 7175-1:2019). ${ }^{45}$ These included, but were not limited to, specifications ensuring the design did not promote lacerations, puncture wounds, choking, strangulation, and entrapment. These were shared with manufacturers to support production. Table 1 describes the three designs.

Trials by Improved Practices. The three prototypes were tested in a TIPs trial. The TIPs process is described in detail in the Supplemental Material S2. In brief, the TIPs trial was used to pilot each of the three HPS prototypes, one each within three households $(N=9)$ in Sidama zone to provide some insights into practical design elements. It also allowed the team to pretest the actual practices that the randomized feasibility trial would engage, providing initial feasibility data on acceptability, time use, and maintenance (correct use and cleaning). The trial enrolled households with an infant aged 10-18 months who were living within the prespecified villages 
TABLE 1

Design specifications for three initial playspace prototypes

\begin{tabular}{|c|c|c|c|c|c|c|c|c|}
\hline Prototype & Floor dimensions & Frame & Wall design & Side height & Slat space & Floor type & Mat design & Other features \\
\hline 1 & $1.4 \mathrm{~m}^{2}$ & Bamboo & $\begin{array}{l}\text { Bamboo poles } \\
25 \mathrm{~cm} \text { panel from floor }\end{array}$ & $70 \mathrm{~cm}$ & $4 \mathrm{~cm}$ & Flat bamboo & $4 \mathrm{~cm}$ foam & Foldable sides \\
\hline 2 & & & $\begin{array}{l}\text { Bamboo poles } \\
25 \mathrm{~cm} \text { panel from floor }\end{array}$ & & $4 \mathrm{~cm}$ & No panel & $\begin{array}{l}\text { Plastic canvas } \\
\text { cover }\end{array}$ & $\begin{array}{l}\text { Sides connected by rope } \\
\text { through drilled holes }\end{array}$ \\
\hline 3 & & & Netted walls & & - & & & \\
\hline
\end{tabular}

$\mathrm{cm}=$ centimeter $\mathrm{m}^{2}=$ meters squared .

and raising domestic animals (cattle and poultry). The trial took place over 1 month, and stages were 1) household identification alongside a local HEW and household visit to recruit and consent households; 2) visit one: HPS allocation and behavior negotiation; 3) visit two: 5 days after the HPS allocation; and 4) visit three: 1 month after visit one. During the first visit, a PIN WASH team member and caregiver agreed a set amount of time for daily use and a cleaning schedulenegotiated as at least 6 hours. It was negotiated that the infant would be in the HPS when the mother was preparing coffee, meals during household activities, when the infant was not sleeping, after breastfeeding or having eaten. Mothers would not leave the infant in the HPS during activities outside the home, such as fetching water. Cleaning behaviors negotiated with all households were to clean the mat using water and soap and to dry the mat in the sun. Mothers agreed to clean the mat when the infant had defecated, when an animal had entered and defecated, and at least once a week. During subsequent visits, the team member used observational and survey data to assess if, how, and why these behaviors were maintained, allowing insight into the barriers and motivators that prevented or enabled HPS use. Time use and other outcomes are described in Section 3. Findings regarding HPS design were incorporated into the final prototype design. The evolution of the playspace design toward the final prototype is shown in Figure 2.

Final prototype design. Design modifications and suggested changes. During the TIPs trial, households with a wooden floored HPS stated they found it harder to clean and were concerned over the risk of rotting in the rainy season. Households with prototypes made with wooden rungs were pleased that the design allowed visibility and the infant to stand by holding. Households with prototypes made of netted sides did not like that infants were not clearly visible. Five households suggested the HPS was slightly too large for their small homes. All households appreciated that the HPS could be folded and taken outdoors (although outdoor use was not assessed). Some households suggested the HPS was quite heavy because of the bamboo structure-however, more caregivers reported it was easy to move and appreciated its sturdiness and durability. Household feedback was mixed regarding the use of rope to tie the sides, but this was deemed the most safe, easy, and affordable solution. Metal hinges were expensive and a potential safety hazard from sharp edges and potential entrapment. There was no reported or observed damage to any HPS, and the rope connecting sides remained correctly fastened in all households. Interestingly, two households hung plastic canvas above the HPS to protect the infant from dust accumulated on the roof from burning firewood.

Final playspace prototype design. Following results of the two workshops and TIPs trial, the research teams further developed the design of the final HPS prototype. Key changes to the final prototype design from the TIPs trial included a reduction of the floor plan from $1.4 \mathrm{~m}^{2}$ to $1.2 \mathrm{~m}^{2}$, foldable walls which were also detachable to allow movement of the HPS, no floor panel to avoid wood rot, and a sufficiently thick mattress covered with canvas to allow for easy cleaning. Although caregivers expressed the need for toys in the TIPs trial, it was decided not to include toys in the feasibility trial. This was to avoid potential safety hazards and also where toys may act as vectors for fecal-oral transmission.

Again, specifications followed design and safety requirements from the ISO standard. ${ }^{45}$ The processes leading to the final design, and final design specifications, are detailed in Table 2. These were sent to a local manufacturer who produced one prototype. The HPS was marginally scaled down to fit smaller households $\left(1.20 \mathrm{~m}^{2}\right)$. All materials, including bamboo, foam, and canvas, were sourced locally with the final cost of 1500 Ethiopian Birr, including labor (approximately \$45). Following build, the final prototype was then tested for safety using a second ISO standard developed for testing purposes (ISO 7175-2:2019). ${ }^{46}$ Relevant safety tests included but were not limited to applying force to test stability and structural integrity, measuring squeeze (pinch) points, ensuring edges were rounded and free of burrs/sharp edges, measuring gap width to mitigate trapping of body parts, and testing flammability of the canvas by flame spread rate and for any flash effects. Finally, prototype safety was checked with a second British standard assessment checklist which provides a structured approach to risk reduction and reducing harm from unintentional injury (Guide 50:2014; see Annex A, assessment checklist in Ref. 45). ${ }^{47}$ The final design successfully passed safety inspections from both the second ISO standard and the British standard assessment checklist. Figure 2 shows the evolution of the design process of the playspace, with the final prototype design in the final row. The final playspace design is shown in Figure 3.

\section{SECTION 3: TESTING FOR FEASIBILITY OUTCOMES}

Feasibility of a HPS was tested via the TIPs trial and the randomized feasibility trial, the CAMPI trial. A TIPs approach (described in Section 2) was used to pilot the three HPS prototypes and alongside providing feedback on the prototype designs, giving initial insights into reasons for acceptability and use and barriers to use among study households. Further details of the methodology are in the Supplemental Material S2. The final prototype design was tested in the CAMPI feasibility trial-a twoarmed, parallel-group, randomized, controlled feasibility trial in 100 households randomized (blinded) to intervention or control (both $n=50$ ). It primarily aimed to describe feasibility of progressing to a full randomly controlled trial and outcomes included recruitment, attrition, adherence, and acceptability. Secondary outcomes included effects on infant health, injury prevention, and 
TABLE 2

Development of design specifications for the final playspace prototype design, including safety considerations

$$
\text { Design process stage }
$$

\begin{tabular}{|c|c|c|c|c|}
\hline \multirow[b]{2}{*}{ Feature } & \multicolumn{2}{|c|}{ Design process stage } & \multirow[b]{2}{*}{ Safety considerations ISO 7175-1:2019 } & \multirow[b]{2}{*}{ Final prototype design } \\
\hline & $\begin{array}{l}\text { Participatory workshop in United } \\
\text { Kingdom; focus group discussion; water, } \\
\text { sanitation, and hygiene partnerships and } \\
\text { learning for sustainability UCD workshop; } \\
\text { manufacturer consultation }\end{array}$ & $\begin{array}{l}\text { Trials by Improved Practices trial } \\
\text { feedback }\end{array}$ & & \\
\hline \multirow[t]{4}{*}{ Structure } & $\begin{array}{l}\text { A wooden structure using } \\
\text { locally sourced material }\end{array}$ & Bamboo structure appreciated & $\begin{array}{l}\text { No element of the cot base } \\
\text { shall break, nor the cot base } \\
\text { become dislodged }\end{array}$ & Bamboo structure \\
\hline & $\begin{array}{l}\text { Easy to wipe down and durable } \\
\text { in heat; does not overheat }\end{array}$ & $\begin{array}{l}\text { Appreciation of local } \\
\text { craftsmanship }\end{array}$ & $\begin{array}{l}\text { No accessible holes between } 7 \\
\text { and } 12 \mathrm{~mm} \text { diameter }\end{array}$ & $1.2 \mathrm{~m}^{2}$ floor plan \\
\hline & $\begin{array}{l}\text { Sides high enough to prevent } \\
\text { animals entering and infants } \\
\text { climbing out }\end{array}$ & $\begin{array}{l}1.4 \mathrm{~m}^{2} \text { floor plan too large for } \\
\text { small households }\end{array}$ & $\begin{array}{l}\text { Edges and protruding parts } \\
\text { shall be rounded or } \\
\text { chamfered and free of burrs }\end{array}$ & Unvarnished and sanded \\
\hline & $\begin{array}{l}\text { Floor plan approximately } \\
1.6 \mathrm{~m}^{2}\end{array}$ & & and sharp edges & \\
\hline \multirow[t]{5}{*}{ Walls/sides } & $\begin{array}{l}\text { Sides and flooring connected } \\
\text { as one piece }\end{array}$ & $\begin{array}{l}\text { Foldable design to take } \\
\text { outdoors }\end{array}$ & $\begin{array}{l}\text { Minimum distance between the } \\
\text { upper side of the mattress } \\
\text { base and the upper edge of } \\
\text { the cot: at least } 500 \mathrm{~mm}\end{array}$ & $\begin{array}{l}\text { Foldable/detachable walls } \\
\text { connected by rope }\end{array}$ \\
\hline & $\begin{array}{l}\text { A solid panel at the bottom } \\
\text { preventing small animals } \\
\text { from entering }\end{array}$ & $\begin{array}{l}\text { Slatted walls which allow } \\
\text { visibility and the infant to pull } \\
\text { themselves up to stand }\end{array}$ & $\begin{array}{l}\text { A mark should indicate the } \\
\text { maximum thickness of the } \\
\text { mattress from the top of the } \\
\text { mattress and the upper side } \\
\text { of the cot }\end{array}$ & Wall height: $70 \mathrm{~cm}$ \\
\hline & $\begin{array}{l}\text { Sides which allow visibility of } \\
\text { the infant, e.g. slatted walls } \\
\text { or netted material }\end{array}$ & $\begin{array}{l}\text { Walls sufficiently high so the } \\
\text { infant cannot climb out }\end{array}$ & $\begin{array}{l}\text { Less than } 60 \mathrm{~mm} \text { between two } \\
\text { adjacent slats }\end{array}$ & Bamboo panel: $25 \mathrm{~cm}$ \\
\hline & $\begin{array}{l}\text { A handrail along the inner wall } \\
\text { which allows the infant to } \\
\text { stand }\end{array}$ & & $\begin{array}{l}\text { No accessible shear and } \\
\text { squeeze points which close } \\
\text { to less than } 18 \mathrm{~mm}\end{array}$ & Space between slats: $4 \mathrm{~cm}$ \\
\hline & $\begin{array}{l}\text { Joints made with simple holes } \\
\text { drilled to size on the bamboo, } \\
\text { connected with rope or a } \\
\text { hinge }\end{array}$ & & $\begin{array}{l}\text { Folding cots shall be equipped } \\
\text { with a locking system to } \\
\text { prevent unintentional folding }\end{array}$ & $\begin{array}{l}\text { A locking mechanism which } \\
\text { locks doors shut during use } \\
\text { A clear, bold mark on the inside } \\
\text { of the playspace indicating } \\
\text { appropriate mattress height }\end{array}$ \\
\hline \multirow[t]{3}{*}{$\begin{array}{l}\text { Floor and } \\
\text { mattress }\end{array}$} & $\begin{array}{l}\text { A mattress, sufficiently padded } \\
\text { with foam }\end{array}$ & $\begin{array}{l}\text { No wooden/bamboo floor to } \\
\text { avoid rot }\end{array}$ & $\begin{array}{l}\text { Maximum rate spread of flame } \\
\text { of textiles, coated textiles or } \\
\text { plastic covering: } 30 \mathrm{~mm} / \\
\text { second; no flash-effect }\end{array}$ & $\begin{array}{l}\text { No floor panel/waterproof } \\
\text { mattress to sit on ground }\end{array}$ \\
\hline & $\begin{array}{l}\text { Lightweight and easy to } \\
\text { remove to clean }\end{array}$ & $\begin{array}{l}\text { Mattress covered with plastic/ } \\
\text { canvas which can easily be } \\
\text { wiped down }\end{array}$ & $\begin{array}{l}\text { If a mattress is supplied with } \\
\text { the cot, there shall be no gap } \\
\text { more than } 30 \mathrm{~mm} \text { between } \\
\text { the mattress and the side } \\
\text { ends }\end{array}$ & Mattress size: $1.17 \mathrm{~m}^{2}$ \\
\hline & $\begin{array}{l}\text { Mattress covering of plastic } \\
\text { burlap tarp material ("shara") } \\
\text { or cotton covering }\end{array}$ & $\begin{array}{l}\text { Mattress thickness of } 4 \mathrm{~cm} \\
\text { deemed sufficient for play }\end{array}$ & & $\begin{array}{l}\text { Sponge filling with cover } \\
\text { (plastic canvas) } \\
\text { Thickness: } 4 \mathrm{~cm}\end{array}$ \\
\hline Stimulation & $\begin{array}{l}\text { Toys, playing materials } \\
\text { Paintings, patterns, floor } \\
\text { designs }\end{array}$ & Toys for stimulation & $\begin{array}{l}\text { No removable parts or items } \\
\text { that the infant can fit in their } \\
\text { mouth }\end{array}$ & $\begin{array}{l}\text { No toys to avoid choking } \\
\text { hazards/vectors for } \\
\text { pathogen transmission }\end{array}$ \\
\hline
\end{tabular}

women's time. The trial methodology and full results are published separately. ${ }^{37}$

The feasibility outcomes from the TIPs and the feasibility trial are described in the following text in terms of acceptability (acceptability of use, acceptability of design, and time use) and adherence (appropriate use, cleaning, and infant hygiene).

Acceptability. The TIPs trial and the feasibility trial showed good overall acceptability among study households who received a HPS. Results for acceptability are separated into acceptability of use, acceptability of design, and playspace time use.

Acceptability of use. There appeared no negative consequences of use, either observed or reported. One household expressed concern over whether the infant was happy inside and reiterated the need for toys. No households expressed any safety concerns. A modified Barrier analysis conducted at the end of the CAMPI trial provided further insight into HPS acceptability through key attitudes and behavioral determinants of use. Methods are described in detail elsewhere ${ }^{48,49}$ as followed by the feasibility trial. ${ }^{37}$ In brief, the Barrier analysis assessed 12 categories of behavioral determinants, exploring all factors which would act as barriers or enablers to HPS use and maintenance. Through certain determinants, the Barrier analysis also demonstrates acceptability. Partial results relating to acceptability are shown in Table 3. Caregivers reported high approval from neighbors $(96.0 \%, n=48)$ and immediate family $(66.0 \%, n=33)$, and low disapproval from friends of parents $(12.0 \%, n=6)$ and neighbors $8.0 \%, n=4)$. The determinants Perceived divine will, Policy, and Culture suggest social acceptability within this context. Many cited 
TABLE 3

Partial Barrier analysis results from the playspace intervention group in the Campylobacter-Associated Malnutrition Playspace Intervention feasibility trial ${ }^{37}$

\begin{tabular}{|c|c|c|c|c|c|c|}
\hline & & \multicolumn{2}{|c|}{ Yes } & No & \multicolumn{2}{|c|}{ Do not know } \\
\hline \multicolumn{2}{|c|}{ BA determinant and question } & $n(50)$ & $\%$ & $n(50)$ & $n(50)$ & $\%$ \\
\hline Perceived divine will & Do you think God approves of you using the HPS? & 48 & 96.0 & 2.0 & 0 & 0.0 \\
\hline $\begin{array}{l}\text { Are ther } \\
\text { from }\end{array}$ & $\begin{array}{l}\text { Are there any community rules which prevent you } \\
\text { from using the HPS? }\end{array}$ & 0 & 0.0 & 100.0 & 0 & 0.0 \\
\hline $\begin{array}{l}\text { Are the } \\
\text { again }\end{array}$ & $\begin{array}{l}\text { Are there any cultural rules that you know of } \\
\text { against using the HPS? }\end{array}$ & 0 & 0.0 & 100.0 & 0 & 0.0 \\
\hline BA determinant & BA question & & Indu & eme & $n(50)$ & $\%$ \\
\hline \multirow[t]{13}{*}{ Perceived positive consequences } & \multirow{13}{*}{$\begin{array}{l}\text { What are the advantages } \\
\text { of using the HPS? }\end{array}$} & \multicolumn{3}{|c|}{ Prevents ingestion of dirt/soil/dirty objects } & 40 & 80.0 \\
\hline & & \multicolumn{3}{|c|}{$\begin{array}{l}\text { Prevents injury (falling, fire, drowning, dust/ } \\
\text { ash, road) }\end{array}$} & 38 & 76.0 \\
\hline & & \multicolumn{3}{|c|}{ Prevents injury from animals } & 29 & 58.0 \\
\hline & & \multicolumn{3}{|c|}{ Decreases/eases mother's workload } & 28 & 56.0 \\
\hline & & \multicolumn{3}{|c|}{ Mother worries less for infant's health/safety } & 26 & 52.0 \\
\hline & & \multicolumn{3}{|c|}{ Eases time pressure for mother/stress } & 23 & 46.0 \\
\hline & & \multicolumn{3}{|c|}{ Improves infant's physical development } & 21 & 42.0 \\
\hline & & Infant/cl & es stay & & 20 & 40.0 \\
\hline & & Prevent & yestion & ces & 20 & 40.0 \\
\hline & & Infant fe & lappy $\mathrm{p}$ & inside/comfortable & 18 & 36.0 \\
\hline & & Prevent & arrhoea/ & disease & 14 & 28.0 \\
\hline & & Protects & m sunlig & & 4 & 8.0 \\
\hline & & Promote & fant's ir & ndence & 2 & 4.0 \\
\hline Perceived negative consequences & What are the disadvantages & No disa & tage & & 26 & 52.0 \\
\hline & of using the HPS? & Cost of & a cleani & aterials & 11 & 22.0 \\
\hline & & Takes u & ace insi & e home & 7 & 14.0 \\
\hline & & Infant $\mathrm{cr}$ & (from bc & & 7 & 14.0 \\
\hline & & Extra ite & clean & & 6 & 12.0 \\
\hline Perceived self-efficacy & What makes it easy for you & Easy to & emble/rc & asy to tie & 27 & 54.0 \\
\hline & to use the HPS? & $\begin{array}{l}\text { Weighs } \\
\text { mattre }\end{array}$ & /easy tc & e (including & 25 & 50.0 \\
\hline & & Good si & akes litt & ce inside & 22 & 44.0 \\
\hline & & Door fac & tes eas & & 14 & 28.0 \\
\hline & & Safe de & /infant $\epsilon$ & visible & 14 & 28.0 \\
\hline & & Design & urages & t play (size/comfort) & 13 & 26.0 \\
\hline & & Bamboc & ucture s & /stable/durable & 12 & 24.0 \\
\hline & & Can be & n outsic & & 8 & 16.0 \\
\hline & & Older cr & en who & latch infant & 8 & 16.0 \\
\hline & & Good w & to slats & courage standing & 4 & 8.0 \\
\hline & What makes it difficult for you & Difficult & ethread & when dismantled & 19 & 38.0 \\
\hline & to use the HPS? & No olde & ildren to & h infant & 16 & 32.0 \\
\hline & & Lack of & & & 16 & 32.0 \\
\hline & & Difficult & hove ou & heavy without help & 8 & 16.0 \\
\hline & & Rope m & ecome & /structure falls & 4 & 8.0 \\
\hline & & Nothing & & & 3 & 6.0 \\
\hline & & Takes u & ace/ho & small & 2 & 4.0 \\
\hline & & No olde & ildren to & h infant & 2 & 4.0 \\
\hline & & Plastic c & get hot $\mathrm{i}$ & & 1 & 2.0 \\
\hline & & Height i & ficient & & 1 & 2.0 \\
\hline Access & What makes it easy for you to keep & Plastic c & ring eas & eaned & 39 & 78.0 \\
\hline & the HPS clean? & $\begin{array}{l}\text { Mattres } \\
\text { remo }\end{array}$ & htweigh & Ill to carry/ & 38 & 76.0 \\
\hline & & Require & le water & & 34 & 68.0 \\
\hline & & Dries qu & $y$ (in/out & & 16 & 32.0 \\
\hline & & Bamboc & tys clear & $y$ to wipe & 14 & 28.0 \\
\hline & & Require & le soap & & 13 & 26.0 \\
\hline & & Plastic c & not $a b$ & mell/urine/dirt & 5 & 10.0 \\
\hline & & Soap ea & o buy/in & nsive & 2 & 4.0 \\
\hline & & Water e & availab & & 2 & 4.0 \\
\hline & What makes it difficult for you & Lack of/ & ense of & ig soap & 28 & 56.0 \\
\hline & to keep the HPS clean? & Water u & ailable a & & 13 & 26.0 \\
\hline & & $\begin{array}{l}\text { Require } \\
\text { cost }\end{array}$ & tra clear & naterials/associated & 12 & 24.0 \\
\hline & & Nothing & & & 6 & 12.0 \\
\hline & & Material & Igh bam & rope/open seams) & 5 & 10.0 \\
\hline Perceived social norms & Who are the people who & Neighbc & & & 48 & 96.0 \\
\hline & approve of you using the HPS? & $\begin{array}{l}\text { Immedia } \\
\text { sibling }\end{array}$ & amily (p & s, grandparents, & 33 & 66.0 \\
\hline
\end{tabular}




\begin{tabular}{|c|c|c|c|c|}
\hline \multirow[t]{11}{*}{ BA determinant } & BA question & Inductive theme & $n(50)$ & $\%$ \\
\hline & & $\begin{array}{l}\text { Health extension workers/HDA/other } \\
\text { government worker }\end{array}$ & 24 & 48.0 \\
\hline & & Husband & 20 & 40.0 \\
\hline & & Friends of parents & 18 & 36.0 \\
\hline & & Aunts/uncles/family-in-law & 18 & 36.0 \\
\hline & & Community members/guests/passers-by & 11 & 22.0 \\
\hline & & Laborer/customers & 3 & 6.0 \\
\hline & Who are the people who & Nobody & 37 & 74.0 \\
\hline & disapprove of you using the & Friends of parents & 6 & 12.0 \\
\hline & HPS? & Neighbours & 4 & 8.0 \\
\hline & & Community members/colleagues/customers & 3 & 6.0 \\
\hline
\end{tabular}

$\mathrm{BA}=$ Barrier analysis; $\mathrm{HDA}=$ Health Development Army; HPS = household playspace.

advantages, related and unrelated to infant health, further demonstrated good acceptability. Caregivers (mothers) mentioned how the HPS prevented geophagy $(80.0 \%, n=40$; $76.0 \%, n=38$ ) and injury from many causes and eased their workload (56.0\%, $n=28$ ) and time pressures $(46.0 \%, n=23)$. Reported disadvantages of using the HPS related to lack of help to supervise the infant $(32.0 \%, n=16)$ and toys $(32.0 \%, n=16)$.

Acceptability of design. Although the three households with prototype three (Table 1) did not like the mesh walls, overall feedback on each prototype was positive. Six mothers commented they felt happy to see their child standing, facilitated by the walls. All mothers commented they were happy the HPS kept their child clean and "for being healthy, to prevent disease." Researchers noted households commented on neighbors' positive feedback ("They really like it and are jealous of it"; "Anyone who saw the playspace become happy and they have positive feedback"). The Barrier analysis indicated mixed acceptability of design among households. The use of the rope to tie the sides was the safest, easiest solution during playspace design. Fifty-four percent $(n=27)$ found this easy to manage, but $38.0 \%(n=19)$ found the rope difficult. The size, door fixture, and structure were largely appreciated.

Playspace time use. Acceptability among households was also assessed in terms of time use of the HPS. The TIPs trial provided initial indications of how often the HPS would likely be used during the day during the feasibility trial. During unannounced visits at 5 days and 1 month, the infant was inside the HPS on arrival in all households. Using the daily activities template (Supplemental Appendix A), daily time use of the HPS was assessed by caregiver interview. Here, caregivers were asked their daily activities and if the HPS was used and from that, time use was estimated. Results are detailed in the following text in Table 4. Only two households used the HPS for the agreed 6 hours by the 5-day visit. By 1 month, all households had reduced the amount of time by at least 1 hour, except one household. As shown, households who initially used the HPS the most reported the greatest decrease in time use. Among reasons for discontinuing use, four households noted an absence of playing materials as a main reason and caregivers removed the infant if they started crying. Two households reported that after 1 month, the infant was walking and was too old to stay inside. Most (six) households suggested the HPS was too big to keep assembled and was a reason for nonuse.

At 2 and 4 weeks in the feasibility trial, primary caregivers were asked open-ended questions to record their activities during the past 24 hours, and if they did or did not use the HPS. Full results are shown in the Supplemental Material S3 and aggregated by category in the feasibility trial paper. ${ }^{37}$ Broadly, use decreased during food preparation and eating and also during visits outside of the home (to church, the market, and neighbors). By contrast, use increased during other activities inside the home (washing clothes and breastfeeding) and outside of the home (preparing enset [false banana] and farming). Second, analyzing HPS use according to daily activities and time period (time of day) suggested use was highest in the mornings (Table 5). Use in the evenings did increase later in the trial.

Adherence (appropriate use and cleaning, infant hygiene). During the TIPs trial, all households reported they had cleaned the HPS at least once during the week (data on exact times not collected). Although all households reported using soap, this could not be confirmed. However, the field team reported that all HPS were clean on observation at both visits with no sign of fecal contamination or dirt. One household had a small plastic dish, and one household a plastic bottle inside the HPS which were visibly dirty. Households with a HPS with no mattress reported it was difficult to clean, and two had put down a plastic sheet.

Table 6 details some HPS use behaviors, infant hygiene, and HPS cleaning practices across study time points in the feasibility trial. Infants in the HPS were mostly watched by an older child $(85.0 \%, n=85$ throughout the trial) and were often left inside when the caregiver went out, although this decreased between study time points $(82.0 \%, n=41$ at 2 weeks to $52.0 \%, n=26$ at 4 weeks). In the absence of toys, caregivers found items for infants to play with, most frequently plastic cups or water bottles $(65 \%, n=65 ; 54.0 \%, n=54$, respectively, throughout the trial). Observational data on infant and HPS hygiene suggest cleanliness improved slightly by 4 weeks, including mattress cleanliness (visible dirt: $12.0 \%$, $n=6-6.0 \%, n=3$, respectively). This contrasts with data on HPS cleaning routines where daily cleaning dropped between 2-4 weeks $(60.0 \%, n=30-32.0 \%, n=16)$ but twice weekly increased $(18.0 \%, n=9-34.0 \%, n=17$, respectively). Using soap alongside water also marginally increased by three respondents $(90.0 \%, n=45-96.0 \%, n=48)$. Further detailed results on appropriate use and cleaning behaviors are reported in the feasibility trial paper. ${ }^{37}$

\section{DISCUSSION}

Design and build (materials and methods). The team designed and built a HPS that was locally produced and acceptable among households in the local context by way of a 
TABLE 4

Daily time use of the playspace during the Trials of Improved Practices trial at 5 days and 1 month

\begin{tabular}{ccccc}
\hline Household number $(N=9)$ & Agreed HPS time use at baseline & Reported HPS time use at 5 days & Reported HPS time use at 1 month & Difference in HPS time use \\
\hline 1 & 6 or more hours & 6 hours & 4 hours & -2 hours \\
2 & & 6 hours & 4 hours & -2 hours \\
3 & & 4 hours & 3 hours & -1 hour \\
4 & 6 hours & 5 hours & -1 hour \\
5 & 4 hours & 4 hours & No change \\
6 & 4 hours & 3 hours & -1 hour \\
7 & & 4 hours & -1 hour \\
8 & & 3 hours & 2.5 hours & -0.5 hour \\
9 & & 3 hours & 2.5 hours & -0.5 hour \\
\hline
\end{tabular}

user-centered design process. The multistage, participatory process, including a FGD, two participatory and usercentered workshops, and a TIPs trial, supported the development of the final prototype. This was then finally tested in a feasibility trial.

The TIPs trial and the modified Barrier analysis in the feasibility trial suggested the design was acceptable and appropriate among study households. It addressed user needs where it was easy to assemble, a good size, the infant was easily visible, and it was easily moved outside. Issues with the design included the rope which attached side: future designs might consider metal hinges but which were decided as a potential safety concern here. Other alternatives might include a latch such as a hook and eye form. Some caregivers reported the HPS was prohibitively heavy; the bamboo structure did add weight; however, more caregivers said it was easily moved and appreciated its sturdiness and durability. The plastic covering and foam mattress were lightweight and easily cleaned, requiring little water and soap, both of which were at times unavailable. During the TIPs and the trial, caregivers expressed the need for toys, and almost all gave infants other objects to play with, which were frequently dirty. Some stimulation for play is clearly required and is a necessary consideration for child psychosocial development. ${ }^{50,51}$ Providing toys with the HPS may have improved time use and adherence. However, in the TIPs and feasibility trial, toys were not included. This was to avoid potential safety hazards and also as potential vectors for fecal-oral transmission. Research shows toys can introduce external bacteria to infants ${ }^{52}$ and where often visibly dirty, were a common hazard in Zambia. ${ }^{33}$ The HPS might offer visual and tactile stimulation within the design: alternatively, caregivers may be counseled on providing nonhazardous toys that can be cleaned regularly. Another potential exposure risk is other children sharing the HPS. Although not recorded in this study, the WASHPaLS team noted this occurred frequently (reported more than observed). ${ }^{42}$ Older children are often required to watch and/or entertain the infant, which may introduce other contamination (including giving items/toys to the infant) and must be considered as sources of infection risk.

Testing and feasibility. Research groups and organizations have recorded a strong demand from caregivers for a hygienic space. ${ }^{19,33,53,54}$ Initial findings from discussions with mothers during the FGD supported this demand. Acceptability outcomes from the TIPs and the feasibility trial suggested that a HPS was highly valued and largely feasible among the study households in terms of acceptability and adherence. The TIPS results suggested households mostly kept the HPS clean and the feasibility trial demonstrated infant and HPS hygiene improved marginally over the trial duration; however, daily cleaning became less frequent. Soap use reportedly increased; however, the modified Barrier analysis suggests accessing soap was difficult, and previous data from this team suggest soap ownership was not common. ${ }^{22,36}$ As reported in the feasibility trial paper, appropriate use and cleaning remained largely consistent across the 4 weeks, but for a small decline. ${ }^{37}$ Providing soap alongside a HPS would be a key consideration in future interventions.

Time use was inconsistent across and within households within the TIPs and feasibility trials. In the former, it decreased by up to 2 hours and in the latter during certain daily activities, although increasing when the caregiver left the home. Further data on time use in relation to daily routines is discussed in the feasibility trial results paper. ${ }^{37}$ Together, results suggest that although compliance during initial use may be high, it will likely fall away over time. When this falls away and why, and what can be done to help avoid this, are key questions moving forward with this research. A behavioral module is therefore a likely necessary component to a future definitive trial or intervention which might improve time-use.

A household playspace as part of a transformative WASH package. As intended by the BabyWASH approach, small but fundamental behavioral changes enabled by tailored, feasible, and acceptable technologies may help improve infant growth. The TIPs trial and the feasibility trial demonstrated that a HPS, where it is able to separate infants

TABLE 5

Reported playspace use and nonuse during daily activities in the past 24 hours across daily time periods: at 2 and 4 weeks in the intervention group in the campylobacter-associated malnutrition playspace intervention feasibility trial

\begin{tabular}{|c|c|c|c|c|c|c|}
\hline & \multicolumn{2}{|c|}{ Morning } & \multicolumn{2}{|c|}{ Afternoon } & \multicolumn{2}{|c|}{ Evening } \\
\hline & Two weeks & Four weeks & Two weeks & Four weeks & Two weeks & Four weeks \\
\hline Reported use of HPS & 154 & 153 & 119 & 153 & 93 & 105 \\
\hline Reported nonuse of HPS & 24 & 32 & 28 & 32 & 42 & 60 \\
\hline
\end{tabular}

HPS = household playspace. Figures are summed from reported daily activities table in Supplemental Material S3. 
TABLE 6

Playspace use behaviors and infant hygiene and playspace cleaning practices in the intervention group in the Campylobacter-Associated Malnutrition Playspace Intervention feasibility trial

\begin{tabular}{|c|c|c|c|c|c|c|}
\hline \multicolumn{7}{|c|}{ HPS use behaviours } \\
\hline & \multicolumn{2}{|c|}{ Two weeks } & \multicolumn{2}{|c|}{ Four weeks } & \multicolumn{2}{|c|}{ Both time points } \\
\hline & $n(50)$ & $\%$ & $n(50)$ & $\%$ & $n(100)^{*}$ & $\% \dagger$ \\
\hline Who watches the infant: another child & 42 & 84.0 & 43 & 86.0 & 85 & 85.0 \\
\hline Mother & 27 & 54.0 & 28 & 46.0 & 55 & 55.0 \\
\hline Husband & 18 & 36.0 & 24 & 48.0 & 42 & 42.0 \\
\hline A grandparent & 0 & 0.0 & 1 & 2.0 & 1 & 1.0 \\
\hline Infant in HPS when leaving the house & 41 & 82.0 & 26 & 52.0 & 67 & 67.0 \\
\hline Other child shares the HPS & 14 & 28.0 & 18 & 36.0 & 32 & 32.0 \\
\hline Who shares the HPS: mother to feed & 6 & 12.0 & 10 & 20.0 & 16 & 16.0 \\
\hline Sister or brother & 4 & 8.0 & 4 & 8.0 & 8 & 8.0 \\
\hline Another child & 2 & 4.0 & 6 & 12.0 & 8 & 8.0 \\
\hline Twin & 1 & 2.0 & 1 & 2.0 & 2 & 2.0 \\
\hline Infant given toys or items to play & 43 & 86.0 & 46 & 92.0 & 89 & 89.0 \\
\hline Items given: plastic cup & 32 & 64.0 & 33 & 66.0 & 65 & 65.0 \\
\hline Plastic water bottle & 27 & 54.0 & 27 & 54.0 & 54 & 54.0 \\
\hline Jerry can cover & 8 & 14.0 & 6 & 12.0 & 14 & 14.0 \\
\hline Empty plastic container & 7 & 13.0 & 5 & 10.0 & 12 & 12.0 \\
\hline Mobile phone & 6 & 12.0 & 6 & 12.0 & 12 & 12.0 \\
\hline Small ball & 5 & 10.0 & 5 & 10.0 & 10 & 10.0 \\
\hline Store-bought plastic toys & 2 & 4.0 & 6 & 12.0 & 8 & 8.0 \\
\hline Book/paper & 2 & 4.0 & 2 & 4.0 & 4 & 4.0 \\
\hline Reasons to remove infant: infant hungry & 49 & 98.0 & 49 & 98.0 & 98 & 98.0 \\
\hline Infant is crying & 44 & 88.0 & 46 & 92.0 & 90 & 90.0 \\
\hline Infant has defecated/urinated & 39 & 78.0 & 37 & 74.0 & 76 & 76.0 \\
\hline To clean the playspace & 30 & 60.0 & 26 & 52.0 & 56 & 56.0 \\
\hline To wash/change infant & 25 & 50.0 & 30 & 60.0 & 55 & 55.0 \\
\hline To breastfeed/feed & 11 & 22.0 & 15 & 30.0 & 26 & 26.0 \\
\hline Infant is sleeping & 4 & 8.0 & 1 & 2.0 & 5 & 5.0 \\
\hline To go out & 1 & 2.0 & 2 & 4.0 & 3 & 3.0 \\
\hline \multicolumn{7}{|l|}{ Infant hygiene and HPS cleaning } \\
\hline \multicolumn{7}{|l|}{ Observational data } \\
\hline Infant visibly dirty upon arrival & 20 & 40.0 & 19 & 38.0 & 39 & 39.0 \\
\hline Infant has dirty hands and nails & 28 & 56.0 & 24 & 48.0 & 52 & 52.0 \\
\hline Visible dirt on mattress & 6 & 12.0 & 3 & 6.0 & 9 & 9.0 \\
\hline Urine or faeces on mattress & 1 & 2.0 & 1 & 2.0 & 2 & 2.0 \\
\hline Animals inside HPS (observed) & 1 & 2.0 & 0 & 0.0 & 1 & 1.0 \\
\hline \multicolumn{7}{|l|}{ Caregiver-reported data } \\
\hline How often clean HPS: every day & 30 & 60.0 & 16 & 32.0 & 46 & 46.0 \\
\hline Twice a week & 9 & 18.0 & 17 & 34.0 & 26 & 26.0 \\
\hline Every other day & 6 & 12.0 & 6 & 12.0 & 12 & 12.0 \\
\hline Only when infant defecates/urinates & 3 & 6.0 & 11 & 22.0 & 14 & 14.0 \\
\hline Only when it is dirty & 2 & 4.0 & 0 & 0.0 & 2 & 2.0 \\
\hline Cleaning materials used: water only & 5 & 10.0 & 2 & 4.0 & 7 & 7.0 \\
\hline Water and soap & 45 & 90.0 & 48 & 96.0 & 93 & 93.0 \\
\hline Animals seen inside HPS: yes & 4 & 8.0 & 0 & 100.0 & 4 & 4.0 \\
\hline Which animals? Cat & 2 & $50.0^{*}$ & 0 & 0.0 & 2 & 2.0 \\
\hline Poultry & 2 & $50.0^{*}$ & 0 & 0.0 & 2 & 2.0 \\
\hline
\end{tabular}

HPS = household playspace.

${ }^{*}$ Calculated as a cumulative total of both time points.

†Percent is of the cumulative total.

from animals and both animal and human feces, may provide some benefit to preventing fecal-oral transmission and thus infection. ${ }^{37}$ However, it is not certain that once given specific enabling technologies, behavior change will automatically follow. The ENGINE study reported inconsistent household use of their locally produced mats where many households remained unaware of the benefits. ${ }^{40} \mathrm{~A}$ participatory design process, as followed here, seeks to avoid that; however, there is also a need to empower the target audience (caregivers) and develop self-efficacy by improving knowledge of risks. ${ }^{55}$ This highlights the importance of appropriate messaging to communities, particularly through existing structures like HEWs and savings groups to improve HPS use. ${ }^{33}$ Moreover, from this, it would be important to incorporate culturally relevant behavior change theory into the design of the intervention from the start. The integration of key behavioral, social, or psychological theories into a theory of change framework can help specify techniques and activities that might strengthen behavior change during the intervention. ${ }^{56}$ This is likely an important consideration during a transformative WASH strategy. Furthermore, where a HPS may serve as one material intervention component to help prevent fecal-oral transmission, it will not block all routes. Other necessary components to help block transmission infection will include safe water, proper food hygiene, and the separation of domestic animals within the home. ${ }^{16,35-37}$

Although true participatory design process in developing settings is difficult to achieve, ${ }^{43}$ the process did help facilitate the development of two outcomes: a product that met user needs and the psychological empowerment of caregivers where they hope to 
improve their infant's health. ${ }^{43}$ The final HPS prototype embodied the needs and requirements of the main users (infants and their caregivers) as well as multiple stakeholders (research teams, donor and implementer communities, and government health workers). This came from a consideration and discussion of local contextual needs, including livelihood patterns, maternal work burden, and caregiving practices and maternal/caregiver needs for their infant's health. These are important factors to consider during BabyWASH intervention design which will dictate if an intervention component is acceptable and adhered to in terms of use and maintenance. Furthermore, the design resulted from a caregiver understanding of infection risk and pathways to infection (primarily through direct fecal-oral transmission) and thus specifically aided in preventing this risk. Notably, as may be of particular importance in a transformative WASH approach, participatory design provides the opportunity to engage and further develop the abilities and skills of the main users (caregivers). ${ }^{43}$ This might encourage a new way of thinking about design processes and facilitate the development of new WASH intervention modalities and technologies.

Limitations and further considerations. Limitations of this preliminary work mostly concern the TIPs trial, including the sample size and data quality. The trial aimed to assess initial behaviors, attitudes, and use within a small number of households. However, this was within a small time frame where the HPS remained novel and high adherence may have been an artifact of this. Although the TIPs trial provided rich data from individual households, it was not designed to explore behaviors or attitudes at the population level. Rather, it serves as a template for how others might design and test similar sorts of interventions intended to form part of a transformative WASH package. Other limitations surrounding data quality and the methodologies assessing use include the use of self-reported data which can hold inherent inaccuracies. The daily activities form to assess playspace use (Supplemental Appendix A) aimed to overcome difficulties of measuring time in a context where hourly intervals are not widely comprehended. However, time use was assessed after the caregiver negotiated an agreed daily period of use; this leaves the strong possibility that reported time use was exaggerated. This cannot be confirmed without observational data.

A further consideration for this type of material intervention is economic (including cost), the ability to scale up production, and household willingness to pay. This research did not assess economic demand which is an important route for further research linking to evaluations of cost effectiveness and market potential. Although the HPS was valued and a demand may exist, this is based on stated preferences with known biases. During their formative follow-up study, the USAID ENGINE Project subsidized the market price of locally produced playmats at almost $50 \%$ and could not see a sustainable business model without the subsidy. ${ }^{40}$ Although by year 4 , savings groups sold out of mats and a supplier was identified, no group purchased a resupply. Seasonality (dictating household income) was also a strong predictor of willingness to pay. ${ }^{40}$ The team in Zambia reported that the plastic HPS was prohibitively expensive which supported the development of a community-built model. ${ }^{33}$ Although this model, constructed using locally sourced material and labor, was deemed affordable, there was no information on cost.

At 1,500 ETB, the final prototype here would be prohibitively expensive to rural households. Although this study aimed to provide a low-cost option of a HPS, this proved difficult. The artisanal manufacture of the HPS meant it was difficult to negotiate a lower cost for bulk production, and there were no real economies of scale. This limits how scalable this prototype is as an option. However, donors, implementers, or research groups aiming to produce this design in larger quantities, or similar material inputs, would benefit from researching the potential for large-scale manufacture which is of importance for a larger trial or for WASH program implementation.

Playspace safety. The design and build of the HPS followed both international safety standards for cots and child's furniture ${ }^{45,46}$ and a British standard safety checklist. ${ }^{47}$ During the TIPs and the feasibility trial, there were no reported concerns from caregivers regarding HPS safety. When discussing safety protocols with households (Supplemental Appendix B), caregivers were instructed to not leave their infant in the HPS for more than an hour. This was to avoid lack of supervision and neglect, where "low-severity lack of supervision" is defined in the Modified Maltreatment Classification System guidelines (further discussed in the Supplemental Material S1). ${ }^{57}$ Although caregivers reported consistent supervision of the infant, this may not have been the case. The feasibility trial noted an increase in caregivers leaving the infant alone toward week 4 , which may have implications for safety and development. ${ }^{37}$ Further observational data are required to understand actual use of the HPS, interactions between the caregiver and infant, and whether any safety concerns arise from poor supervision or extended periods left alone.

\section{CONCLUSION}

Evidence suggests that current WASH intervention design does not adequately improve environmental hygiene, nor sufficiently consider infant behaviors, for better infant health. Where there are multiple sources of fecal contamination, it is unlikely there is one solution. Instead, the WASH sector must identify individual components that are necessary parts of a comprehensive "transformative" intervention, which are at once feasible, practical, and acceptable within the local context and aim to reduce bacterial transmission through a BabyWASH lens. Although caregivers appear aware of the health risks associated with infant fecal ingestion, ${ }^{19,58}$ education alone is unlikely to prevent this without a material component which blocks exposure. ${ }^{59}$ An appropriate technology may thus help drive behavioral change and prevent fecal-oral transmission and infection. This article details the evidence-based design and testing of a BabyWASH playspace-one potential intervention component of a transformative WASH approach. Results from this iterative process suggest a HPS was an acceptable and feasible option among these low-income, rural subsistence households in Ethiopia. In these settings where free-range livestock and domestic animals present an increased risk, a HPS may help reduce fecal-oral transmission during critical, early growth periods.

The design and testing process as detailed in this article responds to a clear need for suitable material inputs in the BabyWASH sector. The article aims to serve as a framework for future, similar HPS interventions in other similar contexts, or for teams developing similar material inputs, and to share and develop best practice within the field. Further research on HPS feasibility must assess use (ideally via observation) over a longer time period, understand reasons for diminishing use, 
and explore methods to address drops in compliance. A tailored behavioral module would be a necessary consideration going forward. Furthermore, data are also needed on any time use "threshold effect" of a HPS which might limit exposure and reduce infection.

Received August 3, 2020. Accepted for publication October 21, 2020. Published online February 1, 2021.

Note: Supplemental materials appear at www.ajtmh.org.

Acknowledgments: We thank all of the People in Need team, Hawassa office, who assisted in data collection, logistics, and field support. We also acknowledge and warmly thank the USAID WASHPaLS and Transform WASH teams who invited us to take part in the design workshop in Amhara and who have shared their work. Finally, the team would also like to thank the study participants who welcomed us into their homes and offered their time.

Financial support: S. B. is jointly funded as a research student by both Cranfield University and people in need, who received funding from the Czech Development Agency for the project.

Authors' addresses: Sophie Budge and Alison Parker, Cranfield Water Science Institute, Cranfield University, Cranfield, United Kingdom, E-mails: s.g.budge@cranfield.ac.uk and a.parker@leeds.ac.uk.Paul Hutchings, Faculty of Engineering and Physical Sciences, University of Leeds, Leeds, United Kingdom, E-mail: p.hutchings@leeds.ac.uk. Camila Garbutt, People in Need UK, London, United Kingdom, E-mail: camila.garbutt@pin-uk.global. Julia Rosenbaum, FHI360, United States Agency for International Development WASHPaLS Project, Washington, DC, E-mail: jrosenbaum@fhi360.org. Tizita Tulu, Concern Worldwide, Addis Ababa, Ethiopia, E-mail: tzt_tulu@yahoo.com. Fitsume Woldemedhin and Mohammedyasin Jemal, People In Need, SNNPR, Hawassa, Ethiopia, E-mails: fitsume.woldemedhin@ peopleinneed.cz and mohammedyasin.jemal@peopleinneed.cz. Bhavin Engineer, B.E. design, Cambridge, United Kingdom, E-mail: bedesignconsultancy@gmail.com. Leon Williams, Centre for Competitive Creative Design, Cranfield University, Cranfield, United Kingdom, E-mail: I.williams@cranfield.ac.uk.

This is an open-access article distributed under the terms of the Creative Commons Attribution (CC-BY) License, which permits unrestricted use, distribution, and reproduction in any medium, provided the original author and source are credited.

\section{REFERENCES}

1. Keusch GT, 2003. The history of nutrition: malnutrition, infection and immunity. J Nutr 133: 336S-340S.

2. Katona $\mathrm{P}$, Katona-Apte J, 2008. The interaction between nutrition and infection. Clin Infect Dis 46: 1582-1588.

3. Fischer Walker C, Perin J, Aryee M, Boschi-Pinto C, Black RE, 2012. Diarrhea incidence in low- and middle-income countries in 1990 and 2010: a systematic review. BMC Public Health 12: 220.

4. GBD 2017 Diarrhoeal Disease Collaborators, 2019. Quantifying risks and interventions that have affected the burden of diarrhoea among children younger than 5 years: an analysis of the Global Burden of Disease Study 2017. Lancet Infect Dis 20: 37-59.

5. Rogawski ET et al., 2018. Use of quantitative molecular diagnostic methods to investigate the effect of enteropathogen infections on linear growth in children in low-resource settings: longitudinal analysis of results from the MAL-ED cohort study. Lancet Glob Heal 6: e1319-e1328.

6. Oriá RB, Murray-Kolb LE, Scharf RJ, Pendergast LL, Lang DR, Kolling GL, Guerrant RL, 2016. Early-life enteric infections: relation between chronic systemic inflammation and poor cognition in children. Nutr Rev 74: 374-386.

7. UNICEF, WHO, 2019. UNICEF, WHO: Joint Child Malnutrition Estimates 2019 Edition-Interactive Dashboard. Available at: https:// data.unicef.org/resources/joint-child-malnutrition-estimatesinteractive-dashboard/. Accessed November 30, 2019.
8. Hatton TJ, 2014. How have Europeans grown so tall? Oxf Econ Pap 66: 349-372.

9. Headey D, Palloni G, 2019. Water, sanitation, and child health: evidence from subnational panel data in 59 countries. Demography 56: 729-752.

10. UNICEF, 1990. Strategy for improved nutrition of children and women in developing countries. United Nations children's fund. Indian J Pediatr 58: 13-24.

11. Fink G, Günther I, Hill K, 2011. The effect of water and sanitation on child health: evidence from the demographic and health surveys 1986-2007. Int J Epidemiol 40: 1196-1204.

12. Spears D, 2013. How Much International Variation in Child Height Can Sanitation Explain? Policy Research Working Paper, No. 6351. Washington, DC: World Bank.

13. Luby SP et al., 2018. Effects of water quality, sanitation, handwashing, and nutritional interventions on diarrhoea and child growth in rural Bangladesh: a cluster randomised controlled trial. Lancet Glob Heal 6: e302-e315.

14. Null $C$ et al., 2018. Effects of water quality, sanitation, handwashing, and nutritional interventions on diarrhoea and child growth in rural Kenya: a cluster-randomised controlled trial. Lancet Glob Health 6: e316-e329.

15. Humphrey JH et al., 2019. Independent and combined effects of improved water, sanitation, and hygiene, and improved complementary feeding, on child stunting and anaemia in rural Zimbabwe: a cluster-randomised trial. Lancet Glob Heal 7: e132-e147.

16. Pickering A, Null C, Winch P, Mangwadu G, Arnold B, Prendergast A, 2019. The WASH benefits and SHINE trials: interpretation of WASH intervention effects on linear growth and diarrhoea. Lancet Glob Health 7: E1139-E1146.

17. Husseini M, Darboe MK, Moore SE, Nabwera HM, Prentice AM, 2018. Thresholds of socio-economic and environmental conditions necessary to escape from childhood malnutrition: a natural experiment in rural Gambia. BMC Med 16: 199.

18. Iráizoz Dominguez E, 2017. BabyWASH and the 1,000 Days. London, UK: Action Against Hunger.

19. Reid B, Orgle J, Roy K, Pongolani C, Chileshe M, Stoltzfus R, 2018. Characterizing potential risks of fecal-oral microbial transmission for infants and young children in rural Zambia. Am J Trop Med Hyg 98: 816-823.

20. Morita T et al., 2017. Mouthing of soil contaminated objects is associated with environmental enteropathy in young children. Trop Med Int Heal 22: 670-678.

21. Perin J et al., 2016. Geophagy is associated with growth faltering in children in rural Bangladesh. J Pediatr 178: 34-39.

22. Budge S, Hutchings P, Parker A, Tyrrel S, Tulu T, Gizaw M, Garbutt C, 2019. Do domestic animals contribute to bacterial contamination of infant transmission pathways? Formative evidence from rural Ethiopia. J Water Health 17: 655-669.

23. Boehm AB et al., 2016. Occurrence of host-associated fecal markers on child hands, household soil, and drinking water in rural Bangladeshi households. Environ Sci Technol Lett 3: 393-398.

24. Harris AR, Pickering AJ, Harris M, Doza S, Islam MS, Unicomb L, Luby S, 2016. Ruminants contribute fecal contamination to the urban household environment in Dhaka, Bangladesh. Environ Sci Technol 50: 4642-4649.

25. Vasco K, Graham JP, Trueba G, 2016. Detection of zoonotic enteropathogens in children and domestic animals in a semirural community in Ecuador. Appl Environ Microbiol 82: 4218-4224

26. El-Tras WF, Holt HR, Tayel AA, El-Kady NN, 2015. Campylobacter infections in children exposed to infected backyard poultry in Egypt. Epidemiol Infect 143: 308-315.

27. George $\mathrm{C}$ et al., 2015. Geophagy is associated with environmental enteropathy and stunting in children in rural Bangladesh. $\mathrm{Am} \mathrm{J}$ Trop Med Hyg 92: 1117-1124.

28. Weisz AJ, Manary MJ, Stephenson K, Agapova S, Manary FG, Thakwalakwa C, Shulman RJ, Manary MJ, 2012. Abnormal gut integrity is associated with reduced linear growth in rural malawian children. J Pediatr Gastroenterol Nutr 55: 747-750.

29. Ngure F et al., 2013. Formative research on hygiene behaviors and geophagy among infants and young children and implications of exposure to fecal bacteria. Am J Trop Med Hyg 89: 709-716. 
30. Pickering AJ, Julian TR, Marks SJ, Mattioli MC, Schwab KJ, Davis $\mathrm{J}, 2012$. Fecal contamination and diarrheal pathogens on surfaces and in soils among Tanzanian households with and without improved sanitation. Environ Sci Technol 46: 5736-5743.

31. Exum NG, Olórtegui MP, Yori PP, Davis MF, Heaney CD, Kosek M, Schwab KJ, 2016. Floors and toilets: association of floors and sanitation practices with fecal contamination in Peruvian amazon Peri-urban households. Environ Sci Technol 50: 7373-7381.

32. WHO/UNICEF, 2019. Position Paper: Implications of Recent WASH and Nutrition Studies for WASH Policy and Practice. Geneva, Switzerland: World Health Organization. Available at: https://www.who.int/water_sanitation_health/news-events/ reflections-series/en/. Accessed November 30, 2019.

33. Reid O, Rie S, Jennifer O, Roy K, Pongolani C, Chileshe M, Fundira $D$, Stoltzfus $R, 2017$. A community-designed play-yard intervention to prevent microbial ingestion: a baby WASH pilot study in rural Zambia. Am J Trop Med Hyg 99: 513-525.

34. Mbuya $\mathrm{M}$ et al., 2015. Design of an intervention to minimize ingestion of fecal microbes by young children in rural Zimbabwe. Clin Infect Dis 61: S703-S709.

35. Budge $S$, Parker A, Hutchings $P$, Garbutt $C$, 2019. Environmental enteric dysfunction and child stunting. Nutr Rev 77: 240-253.

36. Budge $S$ et al., 2019. Domestic poultry ownership is associated with infant Campylobacter spp. infection and malnutrition: formative evidence from Ethiopia. PLoS One 15: e0232541.

37. Budge $S$ et al., 2020. A randomised controlled feasibility trial of a BabyWASH household playspace: the CAMPI study. PLOS Neglected Tropical Diseases (in press).

38. Food for the Hungry, 2019. Evaluation of a Baby WASH Intervention to Reduce Environmental Enteropathy and Impaired Growth in Young Children in Democratic Republic of Congo. Available at: https://www.wvi.org/sites/default/files/FH\% 20Baby\%20WASH\%20RCT\%20PP.pdf.

39. SPRING, 2018. Ghana: Final Country Report 2014-2017. Available at: https://www.spring-nutrition.org/publications/reports/ ghana-final-country-report.

40. Save the Children, 2019. Community-Based Marketing and Sale of WASH Products: An ENGINE Approach to WASH for Nutrition. Addis Ababa, Ethiopia, Engine Technical Note 7, Save the Children, Ethiopia.

41. Rogawski McQuade ET et al., 2019. Impact of water quality, sanitation, handwashing, and nutritional interventions on enteric infections in rural Zimbabwe: the sanitation hygiene infant nutrition efficacy (SHINE) trial. $J$ Infect Dis 221: 1379-1386.

42. Rosenbaum J, Tenaw E, Clemmer R, Israel M, Albert J, 2021. Exploring the use and appeal of playpens to protect infants from exposure to animals, animal feces, and dirt in rural Ethiopia. Am J Trop Med Hyg 104: 346-356.

43. Hussain S, Sanders EBN, Steinert M, 2012. Participatory design with marginalized people in developing countries: challenges and opportunities experienced in a field study in Cambodia. Int J Des 6: 91-109.

44. USAID Water Sanitation and Hygiene Partnerships and Learning for Sustainability (WASHPaLS) Project, 2018. USAID WASHPaLS User-Centered Design Workshop Report: Codesigning a Safe Play Space for Infants and Young Children. Washington, DC: Water, Sanitation, and Hygiene Partnerships and Learning for Sustainability (WASHPaLS).
45. International Organization for Standardization, 2019. ISO 7175-1: 2019 Furniture - Children's Cots and Folding Cots for Domestic Use - Part 1: Safety Requirements. Geneva, Switzerland: International Organization for Standardization.

46. International Organization for Standardization, 2019. ISO 7175-2: 2019 Furniture - Children's Cots and Folding Cots for Domestic Use - Part 2: Test Methods. Geneva, Switzerland: International Organization for Standardization.

47. International Organization for Standardization, International Electrotechnical Commission, 2014. GUIDE 50:2014 Safety Aspects - Guidelines for Child Safety in Standards and Other Specifications. Geneva, Switzerland: International Organization for Standardization.

48. Schmied P, 2017. Behaviour Change Toolkit for International Development Practitioners. Prague, Czech Republic: People in Need.

49. Kittle B, 2017. A Practical Guide to Conducting a Barrier Analysis, 2nd edition. New York, NY: Helen Keller International.

50. Britto PR et al., 2017. Advancing early childhood development: from science to scale 2 nurturing care: promoting early childhood development. Lancet 389: 91-102.

51. Nguyen PH, DiGirolamo AM, Gonzalez-Casanova I, Young M, Kim N, Nguyen S, Martorell R, Ramakrishnan U, 2018. Influences of early child nutritional status and home learning environment on child development in Vietnam. Matern Child Nutr 14: e12468.

52. Vujcic J, Ram P, Hussain F, Unicomb L, Gope PS, Abedin J, Mahmud ZH, Islam MS, Luby SP, 2014. Toys and toilets: crosssectional study using children's toys to evaluate environmental faecal contamination in rural Bangladeshi households with different sanitation facilities and practices. Trop Med Int Heal 19: 528-536.

53. Ngure F, Reid B, Humphrey J, Mbuya M, Pelto G, Stoltzfus R, 2014. Water, sanitation, and hygiene (WASH), environmental enteropathy, nutrition, and early child development: making the links. Ann N Y Acad Sci 1308: 118-128.

54. Save the Children, The Manoff Group Inc, 2014. Water, Hygiene and Sanitation (WASH) in Rural Households in Amhara, Oromia, SNNP and Tigray. A Report on the Findings and Recommendations of a Multi-Method Qualitative Research Study for Social and Behavior Change Communication Programming in Ethiopia. Addis Ababa, Ethiopia: Save the Children.

55. Rapp A, Tirassa M, Tirabeni L, 2019. Rethinking technologies for behavior change: a view from the inside of Human change. ACM Trans Comput Interact 26: 1-30.

56. Arriola KRJ, Ellis A, Webb-Girard A, Ogutu EA, McClintic E, Caruso B, Freeman MC, 2020. Designing integrated interventions to improve nutrition and WASH behaviors in Kenya. Pilot Feasibility Stud 6: 10.

57. English D; LONGSCAN Investigators, 1997. Modified Maltreatment Classification System (MMCS). Norwood, NJ: Ablex Publishing Corporation.

58. Bauza V, Byrne DM, Trimmer JT, Lardizabal A, Atiim P, Asigbee MAK, Guest JS, 2018. Child soil ingestion in rural Ghana frequency, caregiver perceptions, relationship with household floor material and associations with child diarrhoea. Trop Med Int Health 23: 558-569.

59. World Health Organization, UNICEF, USAID, 2015. Improving Nutrition Outcomes with Better Water, Sanitation and Hygiene: Practical Solutions for Policies and Programmes. Geneva, Switzerland: WHO. 